\title{
TRANSIENTE DIFFUSION EQUATION: AN ALTERNATIVE FINITE DIFFERENCE APPROACH
}

\section{EQUAÇÃO DA DIFUSÃo TRANSIENTE: UMA APROXIMAÇÃO ALTERNATIVA PARA DIFERENÇAS FINITAS}

\section{F. OLIVEIRA ${ }^{1}$}

${ }^{1}$ Federal University of Paraná, Department of Mathematic and Engineering, Jandaia do Sul, Paraná, Brazil, marcelo.franco@ufpr.br; ORCID: https://orcid.org/0000-0001-7105-5189

\begin{tabular}{l} 
A R T I C L E I N F O \\
\hline Article history: \\
Received 2020-03-16 \\
Accepted 2020-12-12 \\
Available online 2020-12-12 \\
p a l avra - c h a ve \\
Método das Diferenças Finitas \\
Equação da Difusão \\
Intervalo de Tempo \\
$k$ e y w o r $d s$ \\
Finite Difference Method \\
Diffusion Equation \\
Time Interval \\
\end{tabular}

\begin{abstract}
A B S T R A C T
This work is concerned with development of an alternative finite difference method approach to the solution of the transient diffusion equation. In this approach is assumed that the potential function has a linear variation in some time interval. Thus, an integral with respect to time is carried out in the initial diffusion equation. A constant time weighting function is adopted. The time integration reduces the order of the time derivative that appears in the initial equation. Two numerical examples are presented to verify the accuracy and applicability of the proposed approaches. The results are compared with the standard corresponding analytical solutions.
\end{abstract}

R E S U M O

Esse trabalho foi desenvolvido com uma aproximação alternativa para o Método das Diferenças Finitas (MDF) para solução da equação da difusão transiente. Nessa aproximação, considera-se que a função potencial tem uma variação linear em um dado intervalo de tempo. Assim uma integral em relação ao tempo é aplicada na equação inicial da difusão. Uma função de ponderação constante no tempo é adotada. A integração no tempo reduz a ordem da derivada temporal da equação inicial. Dois exemplos numéricos serão apresentados para verificar a acurácia e a aplicabilidade da aproximação proposta. Os resultados são comparados com a formulação tradicional do MEF e com a solução analítica. 


\section{INTRODUCTION}

The interest in solving several problems in engineering has motivated the appearance of a large number of numerical methods, among which is the Finite Difference Method, referred to by FDM.

Most problems in engineering and physical phenomena, are modeled by systems of equations or differential equations. Therefore, it is necessary to solve these equations, which in simplified cases can be obtained analytically. As explained by Cunha et al. (2016), analytical solutions are generally developed for simplified profiles and shapes, and the result of this simplification there is a loss of quality in the results of the models. However, in situations where the equations are more complex, it is only possible to determine the solution using a numerical method.

Problems of heat transfer, or mass transport caused by external disturbances that spread over a domain, among others, as explained by Dehghan (2004), these are problems of great interest in science and engineering. These problems are mathematically modeled by the diffusion equation.

The analysis of the propagation or distribution of heat plays an extremely important issue in engineering, because according to Greenberg (1998), the diffusion equation governs a wide variety of heat propagation phenomena, such as the electromagnetic waves movement, mass transportation, supersonic fluids. Recently Saksala (2019), published a work where the diffusion equation is used in the study of heat generation and propagation in situations of fractures caused in rocks due to dynamic loads applied. Problems of heat transfer with non-linear model and heat transfer in solar plates for electricity generation, are issues that have been addressed recently (KUHARAT et al., 2018, TORKAMAN et al., 2018).

In order to contribute to the discussion about the numerical solution of the diffusion equation, an alternative integral approach to MDF is presented in this work. For this approach, an integral in time is used and, for convenience, this formulation will be called here MDF-T. From an academic perspective, the development of different formulations for the same method enriches the discussion about method's potential and increases the scope of applications (CUNHA et al., 2016).

The work published by Rahaman et al. (2018) deals with the numerical solution of the diffusion equation using MDF, regarding the stability of the method. A discussion involving a similar approach is initially presented by Carrer et al. (2012) for the diffusion equation and later by Cunha et al. (2016), but in this work the time integral approximation is used within the Boundary Elements Method - BEM for the Diffusive-Advective transport equation. More detailed studies in relation to BEM can be found in (BREBBIA et al., 1984, CARRER \& MANSUR, 2010 and CARRER et al., 2012).

\section{FDM FORMULATION}

The diffusion equation to transient problems over a domain $\Omega$ and limited by a boundary $\Gamma$ is described by Carrer et al. (2012) and is given by

$\frac{\partial^{2} u}{\partial X^{2}}=\frac{1}{K} \frac{\partial u}{\partial t}$

where $u(X, t)$ is the potential or temperature, $K$ is the thermal conductivity of the material $t$ is the time and $X$ represents a point of coordinates $(x, y)$. The initial condition on domain $\Omega$ is given by:

$u(X, 0)=U_{0}(X)$

For the development of the proposed approach in this work, a time interval $\Delta t=t_{1}-t_{0}$ was considered where $t_{0}$ and $t_{1}$ are, respectively, the start and end time. An integration with respect to time is performed in this interval. The equation $(0.1)$ is rewritten as:

$\int_{t_{0}}^{t_{1}} w(t) \frac{\partial^{2} u}{\partial X^{2}} d t=\frac{1}{K} \int_{t_{0}}^{t_{1}} w(t) \frac{\partial u}{\partial t} d t$

Where $w(t)$ is a weighting function given by:

$w(t)=\left\{\begin{array}{l}1 \text { se } t_{0} \leq t \leq t_{1} \\ 0 \text { set } t \notin\left[t_{0}, t_{1}\right]\end{array}\right.$

Assuming that on the time interval the weighting function has a linear variation, as shown by Figure 1. Then the integration in this interval can be approximated according to equation (0.5):

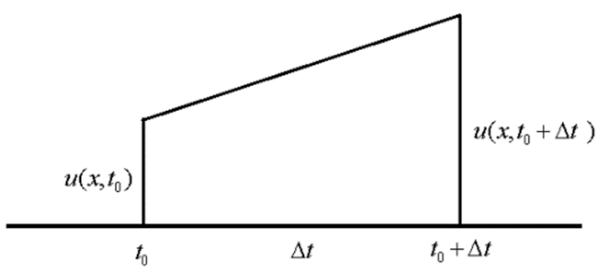

Figure 1 - Linear variation for weighting function over time interval

$\int_{t_{0}}^{t_{1}} u(X, t) d t=\left[u\left(X, t_{0}\right)+u\left(X, t_{1}\right)\right] \frac{\Delta t}{2}$

Applying (0.5) in (0.3) one has:

$\frac{\Delta t}{2}\left(\frac{\partial^{2} u\left(X, t_{0}\right)}{\partial X^{2}}+\frac{\partial^{2} u\left(X, t_{1}\right)}{\partial X^{2}}\right)=\frac{1}{K}\left[u\left(X, t_{1}\right)-u\left(X, t_{0}\right)\right]$ 
It's important to note that with this approach it was possible to reduce the order of the time derivative of the original equation, so the initial condition can be imposed directly on the formulation.

For the solution of equation (0.6), a domain discretization is necessary. Applying an explicit approximation using FDM, in this formulation the $T$ represents the integral over the time interval, in (0.6) one has:

$$
\begin{gathered}
\frac{\Delta t}{2}\left(\frac{u_{i-1}^{k}-2 u_{i}^{k}+u_{i+1}^{k}}{\Delta X^{2}}+\frac{u_{i-1}^{k+1}-2 u_{i}^{k+1}+u_{i+1}^{k+1}}{\Delta X^{2}}\right)= \\
\frac{1}{K}\left[u_{i}^{k+1}-u_{i}^{k}\right]
\end{gathered}
$$

In this preliminary study for a didactic purpose, a one-dimensional domain is considered. Therefore, the equation $(0.7)$ can be rewritten as:

$$
u_{i-1}^{k+1}+\gamma u_{i}^{k+1}+u_{i+1}^{k+1}=(2-\beta) u_{i}^{k}-u_{i-1}^{k}-u_{i+1}^{k}
$$

Where $\gamma=-(2+\beta)$ and $\beta=2 \frac{\Delta X^{2}}{K . \Delta t}$. The letters $k$ and $i$ indicates time and domain points respectively. From equation (0.8) a system of equations can be performed:

$$
\left[\begin{array}{ccccc}
\gamma & 1 & 0 & \cdots & 0 \\
1 & \gamma & 1 & \cdots & 0 \\
0 & 1 & \gamma & \cdots & 0 \\
\vdots & & & \ddots & \\
0 & 0 & 0 & \cdots & \gamma
\end{array}\right]\left[\begin{array}{c}
u_{1}^{k+1} \\
u_{2}^{k+1} \\
u_{3}^{k+1} \\
\vdots \\
u_{N}^{k+1}
\end{array}\right]=\left[\begin{array}{c}
(2-\beta) u_{2}^{k}-u_{1}^{k}-u_{3}^{k} \\
(2-\beta) u_{3}^{k}-u_{2}^{k}-u_{4}^{k} \\
(2-\beta) u_{4}^{k}-u_{3}^{k}-u_{5}^{k} \\
\vdots \\
(2-\beta) u_{N}^{k}-u_{N-1}^{k}-u_{N+1}^{k}
\end{array}\right]
$$

It is important to note that with the presented approach, even applying explicit FDM, the solution is obtained implicitly as shown in equation (0.9) reducing the error of nodal approximations. To verify the results, the proposed formulation will be compared with the analytical solution and the explicit FDM solution, and an example is presented.

\section{NUMERICAL RESULTS}

In this section, the results of the proposed approach in this work are presented in an example with two graphs. The results of FDM-T and FDM will be presented, along with the corresponding analytical solution. Three different values for the diffusion coefficient were adopted, for a better evaluation of the numerical results.

The example consists of a one-dimensional bar with domain $0 \leq x \leq L$, subject to following boundary and initial conditions.

$$
u(0, t)=0
$$

$\frac{d u(L, t)}{d x}=1$

$$
u(x, 0)=0
$$

Analytical solution for this problem is given by Carrer et al. (2012). The results for $u(L)$ are presented in Figure 2.

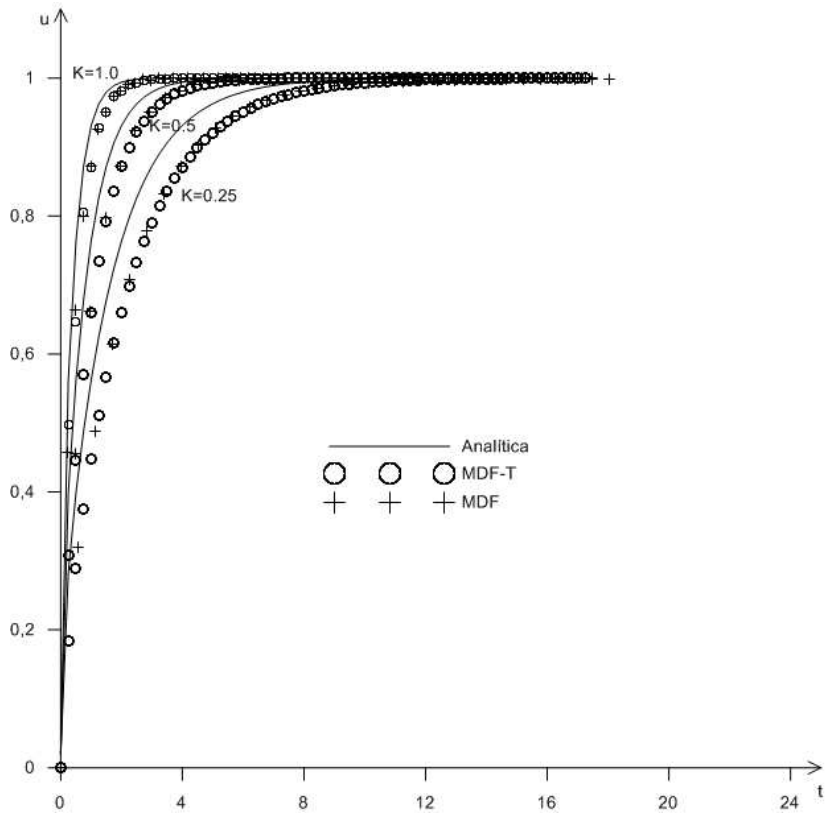

Figure 2 - Potential for the point $x=L$.

For the FDM-T where used $\Delta t=0.25$ in the three cases, and for FDM the follow values were used: For $k=1$, $\Delta \mathrm{t}=0.0352$, for $k=0.5, \Delta \mathrm{t}=0.07$ and $k=0.25, \Delta \mathrm{t}=0.141$. These values were chosen, as they are the highest time interval values in which stable solutions for explicit FDM were obtained.

The results in the graph of Figure 2, show the value for potential at the end of the bar, that is, in $x=L$. A good agreement is observed between the numerical solutions and the exact solution of the problem. It is possible to notice that the presented approximation (FDM-T) shows a more stable solution for much higher $\Delta t$ values than those used in explicit FDM. Solutions using FDM-T are stable at values of $\Delta t<2.0$. This shows the potential of the proposed approach.

It is important to notice that, with the presented formulation, for the same value of $k$, it was possible to obtain stable solutions for much higher $\Delta t$ values concerning the traditional FDM formulation. It can results in a computational gain in more complex analyzes that require more processing time.

Figure 3 presents a graph of the traditional FDM with the values of potential $u$ for the point $x=L$, but using $\Delta t=0.25$ and $k=0.25$. It is possible to notice that the behavior of the solution is not stable, being necessary to use a lower value of $\Delta t$, as shown in the figure 2 . 


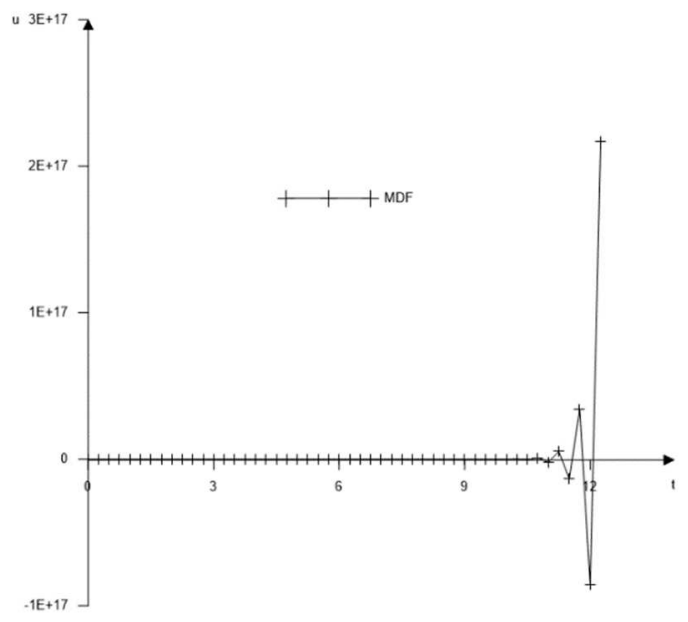

Figure 3 - Potential for the point $x=L$.

Far from intent to bring out a profound discussion about numerical errors, however, can be seen in the graph of figure 3 , that the traditional formulation of FDM did not produce stable results. From the images, it can be concluded that the increase in the time step adopted in the numerical analyzes using FDM must be carefully evaluated, and for the traditional formulation, a higher value for $\Delta t$ produces unstable results. In contrast, the proposed formulation was able to produce results with good precision for higher values.

The graph shown in Figure 4 shows the absolute error in relation to the exact solution for the traditional FDM and the proposed FDM-T in this work. It is possible to notice that there is a significant reduction in error with this proposed approach. This implies that the time step used in the analyzes can be longer, without loss of accuracy in the results. The purpose of error analysis is not to deepen the discussion of numerical errors, but to verify the convergence and accuracy of the methods. It is important to mention that for both formulations, the error tends to zero over time, that is, when the problem tends to the static case. Situation verified in Figure 4.

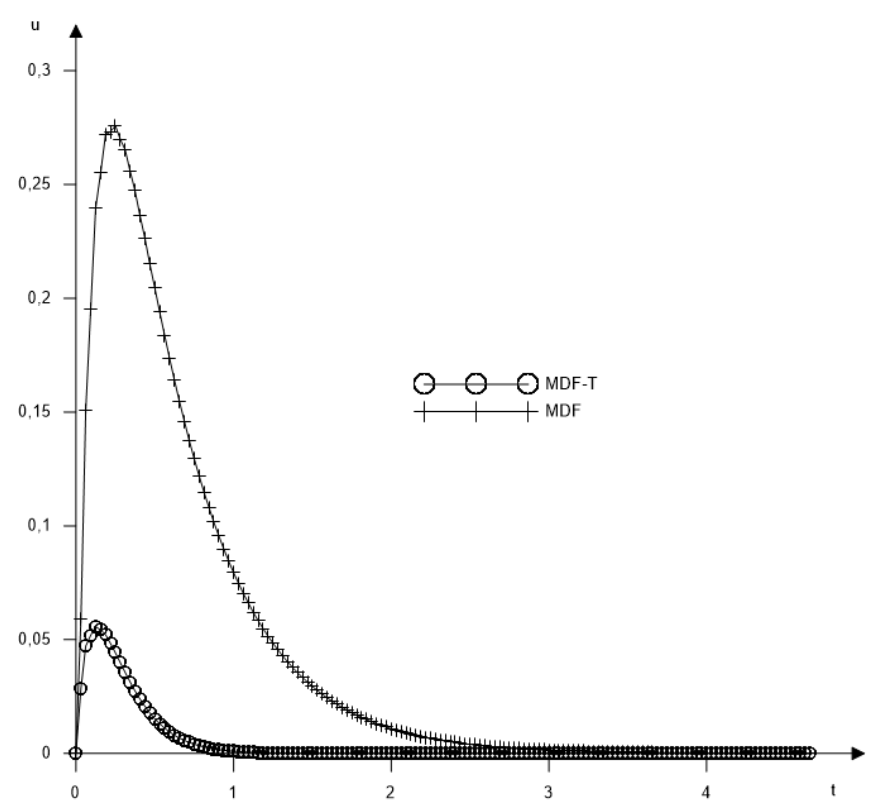

Figure 4 - Absolute error comparison.

\section{CONCLUSIONS}

This article investigated numerically the diffusion equation in two-dimensional domains. The integration over time was able to reduce the order of the derivative. More studies are needed, however, due to the results obtained, this fact helped to improve the stability of the solution and reduce the approximation errors.

The two formulations of FDM presented, proved to be useful in solving diffusion problems. In general, these formulations are versatile, being possible to be applied in several types of problems involving second-order differential equations. The formulation called FDM-T can be considered as an improvement on the traditional formulation of FDM since it employs a better approximation for the time derivative that appears in the equation. This improvement can be seen in the graphs in the example showed.

The results demonstrate the potential of the proposed approach and encourage new applications for the present work, such as application in the wave equation. The wave equation presents greater sensitivity when choosing the time interval, in this sense the approach proposed here appears to be a good alternative for problems involving wave propagation, a subject that will be addressed in future works.

\section{REFERENCES}

BREBBIA, et al., 1984. Boundary element techniques: theory and application in engineering. Berlin, New York, Tokyo: Springer Verlag.

CARRER, J. A. M. \& MANSUR, W. J., 2010. calar wave equation by the boundary element method: a D-BEM approach with constant time-weighting functions. Int $J$ Numer Methods Eng, pp. 1281-1297.

CARRER, J. A. M., OLIVEIRA, M. F., VANZUIT, R. J. \& MANSUR, W. J., 2012. Transient heat conduction by the boundary element method: D-BEM approaches. Int J Numer Methods Eng, pp. 897-913.

CUNHA, C. L. N., CARRER, J. A. M., OLIVEIRA, M. F. \& COSTA, V. L., 2016. A study concerning the solution of advection-diffusion problems by the Boundary Element Method. Engineering Analysis with Boundary Elements, 25 Janeiro, pp. 79-94.

DEHGHAN, M., 2004. On the Solution of an InitialBoundary Value Problem that Combines Neumann and Integral Condition for the Wave Equation. Numerical Methods for Partial Differential Equations, 10 Maio, pp. 24-40.

GREENBERG, M. D., 1998. Advanced Engineering Mathematics. 2 ed. New Jersey: Prentice Hall.

KUHARAT, S., BÉG, O. A., KADIR, A. \& SHAMSHUDDIN, M., 2018. Computational study of heat transfer in solarcollectors with different radiative flux 
models. Heat transfer: Asian Research, 22 Dezembro, pp. 1002-1031.

Li, B. \& Sun, W., 2012. Numerical Analysis of Heat and Moisture Transport with a Finite Difference Method. Numerical Methods for Partial Differential Equations, 5 Março, pp. 226-250.

RAHAMAN, M. M. et al., 2018. Numerical Solution of Diffusion Equation by Finite Difference Method. IOSR Journal of Mathematics, Dezembro, pp. 19-25.

SAKSALA, T., 2019. Numerical modeling of adiabatic heat generation during rock fracture under dynamic loading. Int. Journal for Numerical and Analytic Methods Geomech, Março, p. 14.

TORKAMAN, S., LOGHAMANI, G. B., HEYDARI, M. \& RASHIDI, M. M., 2018. Novel numerical solutions of nonlinear heat transfer problems using the linear barycentric rational interpolation. Heat transfer: Asian Research, Dezembro, p. 27. 